\title{
Experimental Investigation on Effects of Carrier Solvent and Oxide Fluxes in Activated TIG Welding of Reduced Activation Ferritic/Martensitic Steel
}

\author{
Jay J. Vora ${ }^{1}$, and Vishvesh J. Badheka ${ }^{2}$
}

\begin{abstract}
This work attempts to investigate the effect of oxide fluxes on $6 \mathrm{~mm}$ thick Reduced Activation ferritic/martensitic steels (RAFM) during Activated TIG (A-TIG) welding. Six different fluxes $\mathrm{Al}_{2} \mathrm{O}_{3}, \mathrm{Co}_{3} \mathrm{O}_{4}, \mathrm{CuO}, \mathrm{HgO}, \mathrm{MoO}_{3}$, and $\mathrm{NiO}$ were mixed with methanol for conversion into paste and bead-on-plate experiments were then carried out. This study, systematically investigates the influence of oxide-based flux powder and carrier solvent composition on the weld bead shape, geometric shape of weld bead and dominant depth enhancing mechanism in tungsten inert gas (TIG) welding of reduced activation ferritic/martensitic (RAFM) steel. It was inferred from the study that flux $\mathrm{Co}_{3} \mathrm{O}_{4}$ and $\mathrm{MoO}_{3}$ imparted full and secure (more than $6 \mathrm{~mm}$ ) penetration with methanol owing to dual mechanism of reversed Marangoni and arc constriction. The use of methanol imparted good spreadabilty and coverability and ultimately higher peak temperatures were observed with its use owing to stronger depth enhancing mechanisms than use of acetone with same oxide fluxes and welding conditions.
\end{abstract}

Keywords-A-TIG, flux, oxides, penetration, RAFM, temperature, welding

\section{INTRODUCTION}

Welding is by far the most widely used fabrication process for manufacturing of pressure vessels, components for aerospace and defense industry, automobile components etc. Based on the needs and final application there are several number of welding processes developed and studied by the researchers. Out of all these processes, Tungsten inert gas (TIG) welding is the most widely used conventional welding process where high quality welds are required. However, an inherent disadvantage of the process is its limited penetration capability in singles pass autogenous welds [1]. Maximum penetration of around $3 \mathrm{~mm}$ is achieved in single pass and hence in order to weld plates of $6 \mathrm{~mm}$ thick double sided welds or addition of filler metal needs to be carried out. Both of these techniques make the process, time consuming and costly. To encounter this problem, a variant of TIG welding was developed at Paton institute of electric welding in 1960 and was termed as Activated TIG (A-TIG) welding. In this process an activating flux layer comprised of metal oxides, prominently halides, oxides or sulphides is applied on the

Jay J. Vora is with Department of mechanical engineering, school of technology Pandit Deendayal Petroleum University, Raisan, Gandhinagar382007, Gujarat, India.

Dr. Vishvesh J. Badheka is an associate professor in department of mechanical engineering, school of technology Pandit Deendayal Petroleum University, Raisan, Gandhinagar-382007, Gujarat, India surface before welding by mixing the powder with alcohol based carrier solvent such as methanol, ethanol or Acetone [2, 3]. During autogenous welding, this fine layer of flux is melted and vaporized at arc temperatures and penetration capability is reported to be increased up to $300 \%$ while using A-TIG compared to conventional TIG process [4]. Owing to this advantage several researchers have used this technique on different steels with varied chemical composition.

In one the studies Ramkumar et. al. [5] successfully applied the A-TIG welding on similar and dissimilar weldments of super-duplex and austenitic stainless steel welds. Additionally, in one of the separate studies by Ramkumar et. al. [6] used the A-TIG welding technique for Inconel 718 joints. Manu such research on stainless steels [7-10] has been successfully carried out by various researchers which dictates the capability of this new emerging process. Apart from this, several researchers have tried implementing the technique on conventional and advanced alloy steels. Authors Vasudevan et. al. $[4,11,12]$ studied the A-TIG process for P22 steel and P91 steels. In all cases the penetration capability of the TIG welding was enhanced. However, the A-TIG welding is greatly influenced by the chemical composition and hence the technique needs to be developed for new steels with different chemical composition. The use of fluxwas also claimed to reduce the susceptibility to changes in penetrationcaused by cast-to-cast variability in material compositionand reported to produce consistent penetration regardless ofheat-to-heat variations in base metal compositions.

Reduced activation ferritic/martensitic (RAFM) steels are specially developed steels for fusion reactor components as they simplify the waste disposal procedures. RAFM steels are developed by replacing Molybdenum (Mo) by Tungsten (W), Nickel (Ni) by Tantalum (Ta) and reducing the content of Vanadium (V) to decrease its activation tendency. This allows the shallow land burial of reactor components after their service life times are exhausted. The fabrication of this steel for fusion reactor is primarily by welding [13, 14], and hence A-TIG welding of RAFM steel can be considered as an emerging field for study. However limited literatures are available on A-TIG welding of RAFM steels. The most relevant study was carried out the authors [2, 15] where the effect of the oxide fluxes mixed with acetone was reported on $6 \mathrm{~mm}$ thick RAFM steel. It was reported that, fluxes $\mathrm{Co}_{3} \mathrm{O}_{4}$ and $\mathrm{CuO}$ gave full and secure penetration in $6 \mathrm{~mm}$ thick RAFM steel. This was attributed to the simultaneous presence of two different deep penetration mechanisms due to these fluxes. In addition this, a study by reports the use of different carrier 
solvent with same flux and welding conditions. The carrier solvent decides the consistency of the flux layer which in turn dictates the effectiveness of A-TIG process. In this study [3], the author reported the use of methanol and ethanol as a carrier solvent and it effect on A-TIG process. It was reported that methanol and ethanol provided good spreadabilty and coverability and in turn exciting results in terms of depth of penetration. The present study deals with studying weld bead dimension such as DOP, BW, HAZ width and D/w ratio for bead-on-plate welds by A-TIG process using 6 different oxide fluxes such as $\mathrm{Al}_{2} \mathrm{O}_{3}, \mathrm{Co}_{3} \mathrm{O}_{4}, \mathrm{CuO}, \mathrm{HgO}, \mathrm{MoO}_{3}$, and $\mathrm{NiO}$ by using methanol as a carrier solvent and further comparing the results with acetone.

\section{II.EXPERIMENTAL WORK}

\section{A. Base material and fluxes}

As received plates of $6 \mathrm{~mm}$ thick RAFM steel were used in the present study, supplied by M/S Mishra Dhatu Nigam Ltd. Hyderabad, India. The chemical composition of the steel is as shown in table I. Methanol was used as a carrier solvent and the characteristic properties as shown in table II. The oxide fluxes $\mathrm{Al}_{2} \mathrm{O}_{3}, \mathrm{Co}_{3} \mathrm{O}_{4}, \mathrm{CuO}, \mathrm{HgO}, \mathrm{MoO}_{3}$, and $\mathrm{NiO}$ used in present study, were in powdered form.

TABLE I: CHEMICAL COMPOSITION (WT. \%) OF RAFM STEEL USED IN PRESENT STUDY

\begin{tabular}{ccccccc}
\hline \multirow{5}{*}{ Elements } & $\mathrm{C}$ & $\mathrm{Si}$ & $\mathrm{Mn}$ & $\mathrm{P}$ & $\mathrm{S}$ & $\mathrm{Cr}_{\mathbf{y}}$ \\
\cline { 2 - 8 } & 0.1 & 0.02 & 0.54 & 0.003 & 0.002 & 9.0 \\
\cline { 2 - 8 } & $\mathrm{Ti}$ & $\mathrm{Co}$ & $\mathrm{V}$ & $\mathrm{W}$ & $\mathrm{Ta}$ & $\mathrm{B}$ \\
\cline { 2 - 8 } & $<0.005$ & $<0.005$ & 0.23 & 1.42 & 0.15 & $<0.0001$ \\
\cline { 2 - 7 } & $\mathrm{O}$ & $\mathrm{N}$ & $\mathrm{Nb}$ & $\mathrm{Mo}$ & $\mathrm{Al}$ & $\mathrm{Cu}$ \\
\cline { 2 - 7 } & 0.09 & 0.025 & $<0.001$ & $<0.002$ & 0.008 & $<0.002$ \\
\hline
\end{tabular}

TABLE II: CHARACTERISTIC PROPERTIES OF CARRIER SOLVENT

\begin{tabular}{ccc}
\hline Solvent & $\begin{array}{c}\text { Viscosity } \\
\left(20^{\circ} \mathrm{C}, \mathrm{mPa} \cdot \mathrm{s}\right)\end{array}$ & $\begin{array}{c}\text { Vapour pressure } \\
\left(20^{\circ} \mathrm{C}, \mathrm{mm} \mathrm{Hg}\right)\end{array}$ \\
\hline Methanol & 0.817 & 96 \\
Acetone & 0.389 & 184 \\
\hline
\end{tabular}

\section{B. Application of fluxes}

In order to evenly apply the flux on the surface, it was converted to paste form by mixing it with methanol. Base material plate of $6 \mathrm{~mm}$ thick was cut into strips of $75 \times 25$ (mm) for bead on plate trials and flux paste was applied on $10 \mathrm{~mm}$ width at the centre of strip throughout the length with a paint brush. Thickness of flux was approx $0.15 \mathrm{~mm}$ and for having a uniform amount of flux constituents over entire length of strip, the brush was moved in both forward and reverse direction over the desired area until entire flux paste was consumed. In order to measure the peak welding temperatures, a contact type " $\mathrm{K}$ " type thermocouple was fixed at the centre of the plate by drilling a hole of approx. $2 \mathrm{~mm}$ diameter and $3 \mathrm{~mm}$ depth during the welding trials.

\section{Bead-on-plate trials}

Extensive welding trials were conducted in autogenous mode with Panasonic make GTAW power source having capacity of 200 A with $25 \%$ duty cycle and customized special purpose machine for torch movement. The welding parameters used for the study are shown in table III. In order to compare the effect of oxide fluxes, samples were welded with same operating conditions by applying six oxide fluxes individually. Additionally, the welding conditions were kept the same as used by the authors in their previous study with acetone s a carrier solvent. After welding, the macrostructures of the welded samples were developed by conventional metallographic techniques and different weld bead dimensions such as DOP, BW and HAZ width were measured using a travelling vernier microscope.

\begin{tabular}{cc} 
TABLE III: WELDING PARAMETERS FOR BEAD ON PLATE TRIALS \\
\hline Welding current & $200 \mathrm{~A}$ \\
Crater current & $200 \mathrm{~A}$ \\
Travel speed & $100 \mathrm{~mm} / \mathrm{min}$ \\
Electrode type & Tungsten $(2 \%$ Thoriated $)$ \\
Electrode diameter & $2.9 \mathrm{~mm}$ \\
Electrode Angle & $18-20^{\circ}($ Blunt ground at tip) \\
Arc Gap & $2-3 \mathrm{~mm}$ \\
Shielding Gas & Argon $(99.999 \%$ purity $)$ \\
Gas flow rate & $10-12 \mathrm{~L} / \mathrm{min}$ \\
Welding position & $1 \mathrm{G}(\mathrm{Flat})$ \\
Electrode extension & $5-6 \mathrm{~mm}$ \\
Nozzle diameter & $8 \mathrm{~mm}$ \\
\hline
\end{tabular}

\section{RESULTS AND DISCUSSION}

The present study investigates the effect of oxide fluxes mixed with methanol on the A-TIG welding of RAFM steel using six different oxide fluxes. Furthermore, the comparison between the effectiveness of acetone and methanol as a carrier solvent has also been done.

\section{A. Effect on Weld macrostructures}

The macrostructures developed are as shown in figure 1. It can be seen that, full and secure penetration is obtained with the use of fluxes $\mathrm{Co}_{3} \mathrm{O}_{4}$ and $\mathrm{MoO}_{3}$. From the figure it can also be observed that the weld bead shape for these two fluxes is different than the characteristic TIG welded bead shape. The bead shape is narrow and deep for A-TIG welding whereas with the TIG welding the bead shape is shallower and wider [2]. Thus it can observed that an evident mechanism is present with the use of oxide fluxes in A-TIG welding which is elaborated in coming sections.

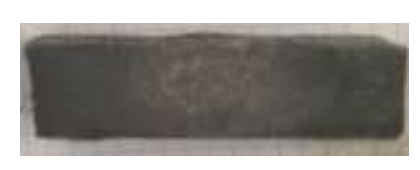

(a) No-Flux

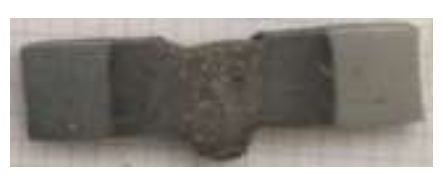

(b) $\mathrm{Co}_{3} \mathrm{O}_{4}$

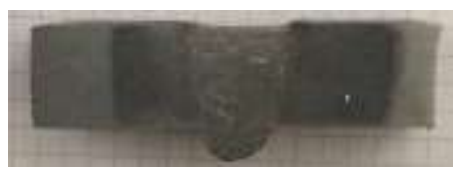

(c) $\mathrm{MoO}_{3}$

Fig. 1Macrostructures of Bead-on-plate weldments

\section{B. Effect on Weld Bead dimensions}

The weld bead dimensions as measured by the travelling vernier microscope are as shown in table IV.It can be seen from the table that fluxes $\mathrm{Co}_{3} \mathrm{O}_{4}$ and $\mathrm{MoO}_{3}$ gave penetration of 
more than $6 \mathrm{~mm}$. Hence a full and secure penetration is obtained with the use of these oxide fluxes. Furthermore, it can also be observed that the $\mathrm{D} / \mathrm{w}$ ratios for both these fluxes are found to be near to unity. Near to unity $\mathrm{D} / \mathrm{w}$ ratio indicates that the DOP is increased at the expense of BW, which is a highly desirable condition. It proves that the most popular activation mechanism of reversed Marangoni flow is present with the use of these fluxes and these fluxes can further be termed as activating fluxes. The reversed Marangoni flow changes the direction of fluid flow (molten metal in present case) during welding to radially inwards and hence a deeper and narrower bead is obtained. It can also be noted from the table IV that flux $\mathrm{NiO}, \mathrm{CuO}$ and $\mathrm{Al}_{2} \mathrm{O}_{3}$ gave an increase in DOP compared to DOP of $3.6 \mathrm{~mm}$ with autogenous TIG welding without flux. Thus it can be attributed that, there is an evident Marangoni effect present with these fluxes, however it is independently not capable of giving full and secure penetration. Thus, there must be an additional mechanism [2] responsible for deeper penetration with fluxes $\mathrm{Co}_{3} \mathrm{O}_{4}$ and $\mathrm{MoO}_{3}$ which is discussed in next section.

TABLE IV: EFFECT ON WELD BEAD DIMENSIONS AND PEAK

\begin{tabular}{cccccc}
\multicolumn{5}{c}{ WELDING TEMPERATURE } \\
\hline Flux & $\begin{array}{c}\mathrm{BW} \\
(\mathrm{mm})\end{array}$ & $\begin{array}{c}\text { DOP } \\
(\mathrm{mm})\end{array}$ & $\begin{array}{c}\mathrm{HAZ} \\
\text { Width } \\
(\mathrm{mm})\end{array}$ & $\mathrm{D} / \mathrm{w}$ & $\begin{array}{c}\text { Peak } \\
\text { Temperature } \\
\left({ }^{\circ} \mathrm{C}\right)\end{array}$ \\
\hline $\mathrm{Al}_{2} \mathrm{O}_{3}$ & 8.9 & 5.0 & 4.1 & 0.56 & 606 \\
\hline $\mathrm{Co}_{3} \mathrm{O}_{4}$ & 7.1 & 7.1 & 4.1 & 1.00 & 830 \\
\hline $\mathrm{CuO}$ & 10.1 & 4.5 & 2.9 & 0.45 & 690 \\
\hline $\mathrm{HgO}$ & 9.0 & 3.1 & 3.5 & 0.34 & 640 \\
\hline $\mathrm{MoO} 3$ & 7.1 & 7.5 & 4.1 & 1.06 & 802 \\
\hline $\mathrm{NiO}$ & 6.1 & 5.1 & 2.9 & 0.84 & 616 \\
\hline
\end{tabular}

\section{Effect on Peak Welding Temperatures}

From table IV it can be observed that the peak temperatures achieved with the use of fluxes $\mathrm{Co}_{3} \mathrm{O}_{4}$ andMoO 3 are on higher side compared to other fluxes. Thus it can be recommended that another mechanism of arc constriction was present. Arc constriction mechanism tends to focus the arc energy towards the centre by altering the arc shape. Researchers have observed the arc images with A-TIG welding and a clear demarcation in the physical shape have been observed under this mechanism. As a consequence of the same, the total arc energy which was same in all cases (all fluxes) was concentrated at the centre and the peak temperatures were increased even thought the welding conditions and parameters were same. This directed nature of arc assisted in melting the metal efficiently and increasing the DOP. These can be compared with the phenomenon which occurs in laser beam welding. Contrary to the same, the peak temperatures reported with the use of other fluxes were on lower side and hence no flux was able to impart full and secure penetration. Thus this study supports the authors' theory of dual mechanism in ATIG welding [2].

\section{Comparison of Acetone and methanol as a carrier solvent}

The experimental data obtained from present study was compared with the already published[2] data by the authors and a meaningful comparison was observed from both these studies. Figure 2 gives the comparison on DOP obtained with the use of same oxide fluxes on A-TIG welding of RAFM steels. It can be observed that flux $\mathrm{Co}_{3} \mathrm{O}_{4}$ was capable of giving full penetration in $6 \mathrm{~mm}$ thick RAFM plate with use of both methanol and acetone. However, flux $\mathrm{CuO}$ and $\mathrm{MoO}_{3}$ imparted full penetration only with acetone and methanol respectively. Similarly from figure 3 it can be noted that BW values obtained with the use of acetone is higher than that obtained with methanol.

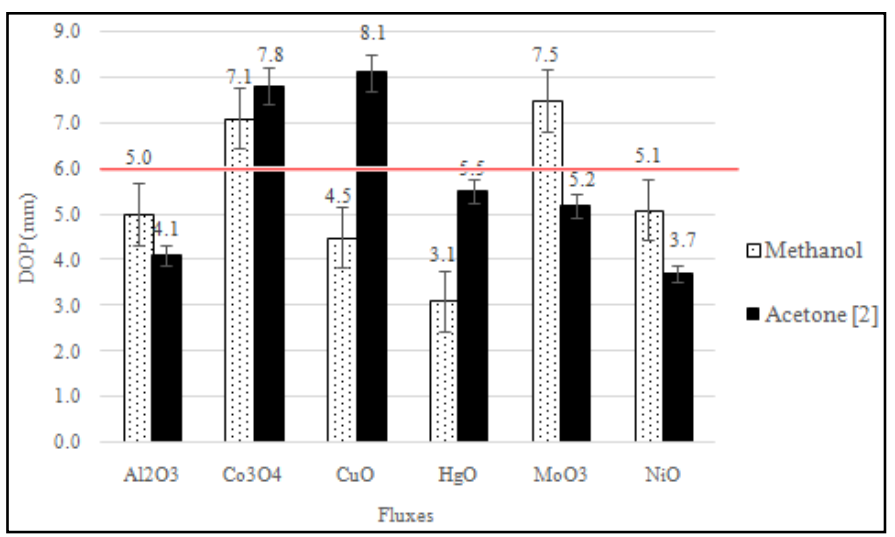

Fig. 2. Comparison of DOP

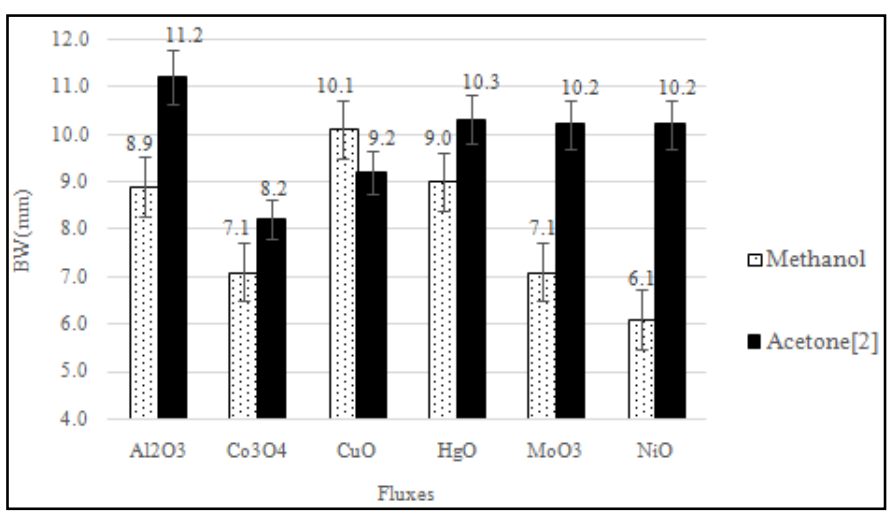

Fig. 3. Comparison of BW

Both these phenomenon can be attributed to the fact that, acetone has a tendency to evaporate more readily than methanol after application on the plate surface. Thus wet flux paste is converted to dry oxide flux layer immediately with acetone compared to methanol. Furthermore, during the autogenous TIG welding, the shielding environment was that of argon. When the torch is in motion, during welding, strong pressure and flow rate of argon gas in use tends to thrust the oxide powder away from the weld surface. Owing to that, effective oxide flux layer (particles) available during welding was less with acetone than methanol. Hence the depth enhancing mechanism are slightly less powerful in acetone compared to methanol. Due to this slight increase in BW was observed with the use of acetone owing to reduced activation mechanism compared to methanol. 


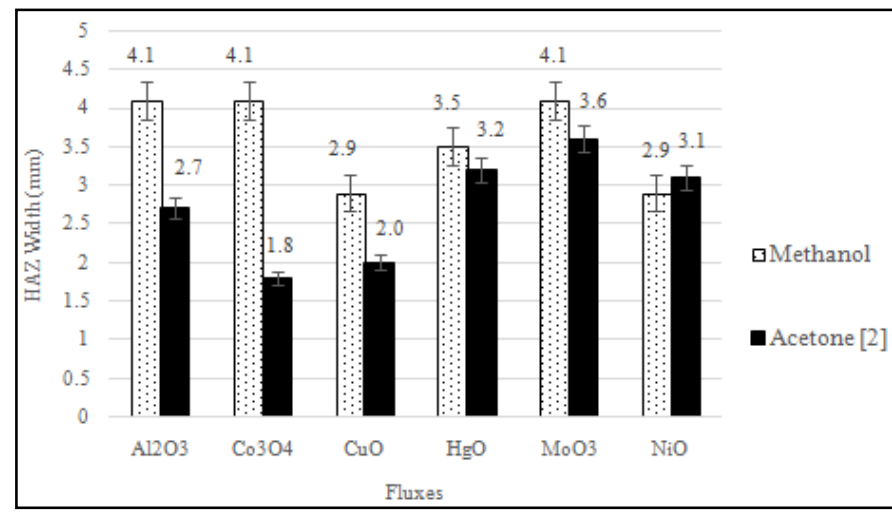

Fig. 4. Comparison of HAZ Width

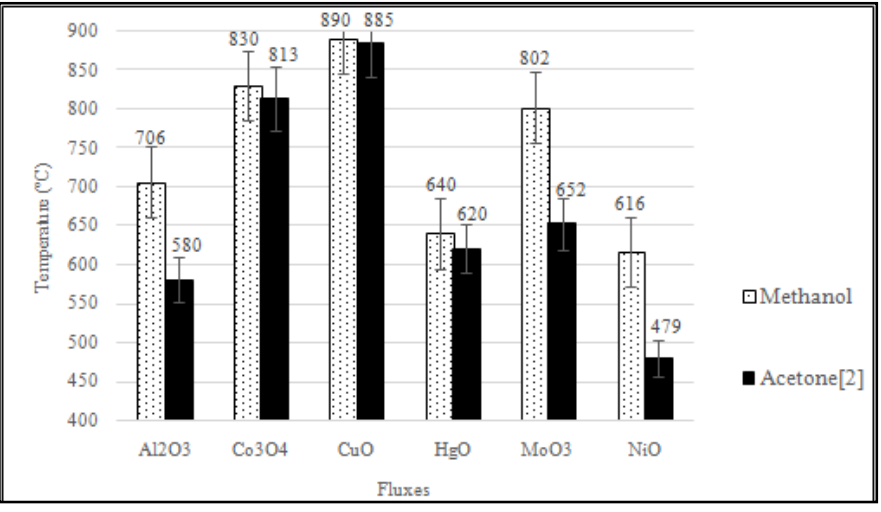

Fig. 5. Comparison of Peak welding temperatures

Another argument to the same can be given by observing figure 4 and figure 5 which compares the HAZ width values and peak welding temperaturesrespectively. As discussed as the flux components available with acetone are less compared to methanol, arc energy available for welding is slightly less and hence HAZ width and peak welding temperature are less compared to methanol.

\section{CONCLUSIONS}

The effect methanol as a carrier solvent in addition to six different oxide fluxes on A-TIG welding of RAFM steels were analyzedand comparison between the effect of carrier solvent was presented. From the study, following conclusions can be made.

1) Fluxes $\mathrm{Co}_{3} \mathrm{O}_{4}$ andMoO 3 are capable of giving full and secure penetration of $7.1 \mathrm{~mm}$ and $7.5 \mathrm{~mm}$ respectively with methanol in $6 \mathrm{~mm}$ thick RAFM steel plates.Apart from reversed Marangoni, additional mechanism of arc constriction was present. Under the synchronized effect of these two depth enhancing mechanisms, enhanced penetration was achieved.

2) Fluxes $\mathrm{NiO}, \mathrm{CuO}$ and $\mathrm{Al}_{2} \mathrm{O}_{3}$ enhanced the penetration capability of TIG welding processes, however full penetration was not achieved because of the absence of arc constriction mechanism. This was evident by lower values of peak temperatures at same welding conditions.

3) $\mathrm{Co}_{3} \mathrm{O}_{4}$ was able to impart full penetration in $6 \mathrm{~mm}$ thick RAFM steel plate with acetone as well as methanol as the carrier solvent. However, flux $\mathrm{CuO}$ and $\mathrm{MoO}_{3}$ imparted full penetration only with acetone and methanol respectively.

4) Methanol imparts good spreadabilty as well as coverability to the flux paste. Also methanol tends to evaporate less likely compared to acetone and hence effective flux ingredients available for A-TIG welding is more with the use of methanol and hence comparatively stronger mechanisms are present with the methanol.

\section{ACKNOWLEDGMENT}

Authors would like to extend their gratitude to BRFST and IPR Gandhinagar, for sponsoring the project via project number NFP-08/MAT/01 and for extending their kind support.

\section{REFERENCES}

[1] Kumar, S.A. and P. Sathiya, Experimental Investigation on A-TIG Welding Process of Incoloy $800 \mathrm{H}$. Materials and Manufacturing Processes,2015(just-accepted).

[2] Vora, J.J. and V.J. Badheka, Experimental investigation on mechanism and weld morphology of activated TIG welded bead-on-plate weldments of reduced activation ferritic/martensitic steel using oxide fluxes. Journal of Manufacturing Processes, 2015. http://dx.doi.org/10.1016/j.jmapro.2015.07.006

[3] Tseng, K.-H., Development and application of oxide-based flux powder for tungsten inert gas welding of austenitic stainless steels. Powdertechnology, 2013. 233: p. 72-79. http://dx.doi.org/10.1016/j.powtec.2012.08.038

[4] Arivazhagan, B. and M. Vasudevan, Studies on A-TIG welding of 2.25 Cr-1Mo (P22) steel. Journal of Manufacturing Processes, 2015. 18: p. 55-59. http://dx.doi.org/10.1016/j.jmapro.2014.12.003

[5] Ramkumar, K.D., et al., Investigations on structure-property relationships of activated flux TIG weldments of super-duplex/austenitic stainless steels. Materials Science and Engineering: A, 2015. 638: p. 6068. http://dx.doi.org/10.1016/j.msea.2015.04.041

[6] Ramkumar, K.D., et al., Effect of flux addition on the microstructure and tensile strength of dissimilar weldments involving Inconel 718 and AISI 416. Materials \& Design, 2015. 87: p. 663-674. http://dx.doi.org/10.1016/j.matdes.2015.08.075

[7] Ramkumar, K.D., et al., Effect of autogeneous GTA welding with and without flux addition on the microstructure and mechanical properties of AISI 904L joints. Materials Science and Engineering: A, 2015. 636: p. 19.

http://dx.doi.org/10.1016/j.msea.2015.03.072

[8] Ramkumar, K.D., et al., Experimental investigations on the $\mathrm{SiO} 2$ fluxassisted GTA welding of super-austenitic stainless steels. The International Journal of Advanced Manufacturing Technology, 2015: p. $1-12$. http://dx.doi.org/10.1007/s00170-015-7876-6

[9] Tathgir, S. and A. Bhattacharya, Activated-TIG Welding of Different Steels: Influence of Various Flux and Shielding Gas. Materials and Manufacturing Processes, 2015(just-accepted).

[10] Yi, Y.Y., et al. Study on A-TIG Welding Technology for $12 \mathrm{~mm}$ Thick 304 Stainless Steel Plate. inMaterials Science Forum. 2015. Trans Tech Publ.

[11] Arivazhagan, B. and M. Vasudevan, A study of microstructure and mechanical properties of Grade 91 steel A-TIG weld joint. Journal of materials engineering and performance, 2013. 22(12): p. 3708-3716. http://dx.doi.org/10.1007/s11665-013-0694-9

[12] Arivazhagan, B. and M. Vasudevan, A comparative study on the effect of GTAW processes on the microstructure and mechanical properties of P91 steel weld joints. Journal of Manufacturing Processes, 2014.16(2): p. 305-311. http://dx.doi.org/10.1016/j.jmapro.2014.01.003

[13] Ku, D.Y., et al., TIG and HIP joining of Reduced Activation Ferrite/Martensitic steel for the Korean ITER-TBM. Journal of Nuclear Materials, 2011.417(1): p. 67-71. http://dx.doi.org/10.1016/j.jnucmat.2010.12.169 
[14] Aubert, P., et al., Review of candidate welding processes of RAFM steels for ITER test blanket modules and DEMO. Journal of Nuclear Materials, 2011. 417(1): p. 43-50 http://dx.doi.org/10.1016/j.jnucmat.2010.12.248

[15] Vora, J.J. and V.J. Badheka., Improved Penetration with the Use of Oxide Fluxes in Activated TIG Welding of Low Activation Ferritic/Martensitic Steel. Transactions of Indian institute of metals, DOI: $10.1007 / \mathrm{s} 12666-016-0835-6$.

http://dx.doi.org/10.1007/s12666-016-0835-6 